\title{
Mutual Coupling Reduction with a Wideband Planar Decoupling Structure for UWB MIMO Antennas
}

\author{
Alaa H. Radhi ${ }^{1}$, R. Nilavalan ${ }^{1}$, Yi Wang ${ }^{2}$, H. S. Al-Raweshidy ${ }^{1}$, Amira A. Eltokhy ${ }^{2}$ and Nur Ab Aziz ${ }^{1}$ \\ ${ }^{1}$ College of Engineering, Design \& Physical Science, Brunel University, London, UK. \\ ${ }^{2}$ Department of Engineering Science, University of Greenwich, Chatham Maritime, Kent, UK. \\ Email: Alaa.Radhi@brunel.ac.uk
}

A new planar MIMO antenna for UWB applications is presented. The proposed antenna operates over the frequency band from 3.1 to $10.6 \mathrm{GHz}$ and it consists of two identical circular monopoles on an $\mathrm{FR}_{4}$ substrate. The wide isolation is achieved through a novel planar decoupling structure that is being inserted between the dual antennas. Moreover, a centre slot is etched on the common ground to further increase isolation. The effectiveness of the decoupling structure is analysed, and performance study has performed to investigate the mutual coupling reduction. A good isolation of more than $31 \mathrm{~dB}$ has been achieved through the entire UWB band (more than $12 \mathrm{~dB}$ improvement over the reference antenna).The proposed UWB antenna with and without the wideband decoupling structure is being investigated and verified both numerically and experimentally. The measurement results of the proposed UWB-MIMO antenna are in good agreement with the simulation results. The proposed UWB antenna has been compared with previous works regarding antenna size, geometric complexity, bandwidth and isolation level. The proposed antenna has some outstanding characteristics such as a geometric simplicity, compact size, broad bandwidth and low correlation which give the antenna an excellent diversity performance and a good candidate for UWB applications.

Keywords: Ultra Wide Band (UWB), mutual coupling reduction, monopoles Antenna, Multiple-Input-Multiple-Output (MIMO).

\section{INTRODUCTION}

Microstrip antenna is considered an important component in modern UWB systems; recently researchers have developed many different antenna designs for UWB applications with wide impedance bandwidth, reasonable gain, linear phase and stable radiation characteristics across the entire UWB frequency range. These developments in modern wireless communication systems have imposed additional challenges to produce new designs that are miniaturised and have a good broadband performance $[1,2]$.

In MIMO systems, multiple antenna elements are required at both receiver and transmitter side [3]. As a result, the design of two or more antennae on small mobile terminals for the MIMO systems is more challenging compared to the design of the conventional single antenna [4]. However, installing multiple antenna elements in the small space available in portable devices will inevitably cause severe mutual coupling and significantly degrade the diversity performance. Thus one of the main challenges in employing MIMO systems in mobile devices is the design of small antennas with low mutual coupling level [5].With the rapid expansion of wireless MIMO communication systems, the demand for low profile, wide bandwidth, and high isolation between antenna elements has increased to maintain a good diversity performance. High isolation (Low mutual coupling level) between the adjacent antenna elements is one of the essential requirements for any recent MIMO antenna implementation [4]. Mutual coupling between closely spaced antennas is caused by Radiation Emission (RE) through the electromagnetic coupling and Conduction Emission (CE) through a common conductor such as the ground plane [1].

When a multiple-element antenna embeds into the small mobile terminal, it should be compact (low profile) as much as possible. Additional requirements should also be met, e.g., lowest mutual coupling (higher isolation between antennas) and robustness while maintaining the compactness with acceptable diversity performance for multiple antennas [3]. Therefore, in designing the antenna for the mobile terminal, it is important to balance the trade-off between compactness and performance [2].

In recent years, several techniques have been employed to achieve these objectives [5]. Among the main techniques that has been extensively studied and discussed in the literature for the mutual coupling reduction are: Neutralisation line (NL) method [3,18], insertion of miniaturised double layer Electromagnetic Band Gap (EBG) structure [4], Defected Ground Structure (DGS) [5,19], implementation of separated ground plane [6], spatial and angular variations techniques [8-12], parasitic elements were also inserted between the elements to improve the isolation [22], and inserting a stub structure on the shared ground plane [13-16] etc.

A new planar MIMO antenna for UWB applications is presented in this paper. The proposed UWB antenna exploits the approach of using a compact wideband planar decoupling structure in between to augment the isolation level. The proposed UWB-MIMO antenna shows good impedance characteristics in the frequency band range of $3.1-10.6 \mathrm{GHz}$ with excellent isolation characteristics, the antennas are simulated with commercially available HFSS software version 17.0 which is mainly based on finite element methods.

The remainders of the paper are organized as follows: Section II briefly describes the design procedure of the proposed UWB-MIMO antenna. That followed by design simulation, performance study, and the significance of the proposed wideband decoupling structure are also shown in 
the Section III. Section IV outlines the antenna fabrication and measurement results. In Section $\mathrm{V}$ a comparison with other previous works is carried out and summarised. Finally, some conclusive comments and further scope are expressed in Section VI.

\section{ANTENNA DESIGN}

\section{A) UWB-MIMO Antenna Configuration}

In microstrip antenna array designs, circular and semicircular monopole antennas have more impedance bandwidth compared to rectangular, triangular, square and hexagonal monopole antennas [2]. The designed and fabricated UWBMIMO antennas without the proposed wideband decoupling structure are shown in Fig. 1.

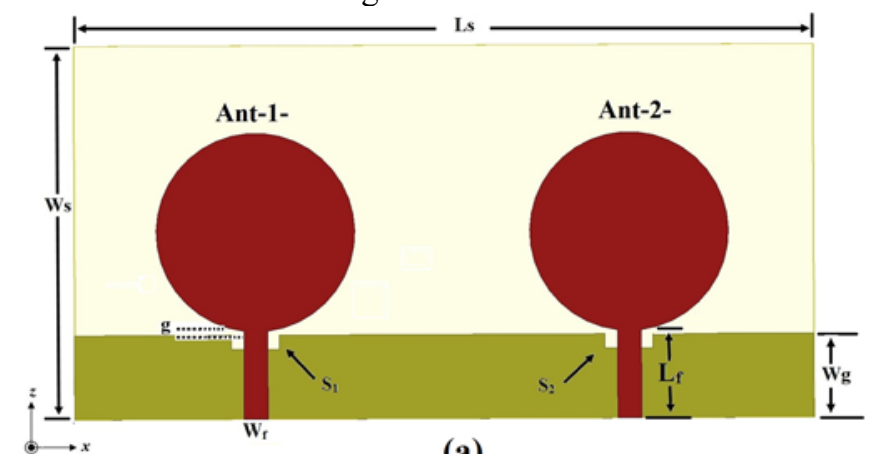

(a)

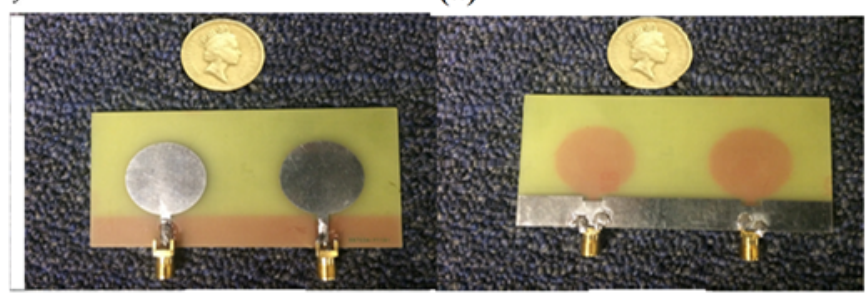

(b)

Fig. 1. A proposed UWB-MIMO antenna without the decoupling structure. (a) Schematic Antenna layout (Top view) (b) A prototype of fabricated antenna (Top and Back view).

It consists of two symmetrical circular-shaped monopole radiating elements [20] denoted as Ant-1- and Ant-2-, which are located on the same sides of the common $\mathrm{FR}_{4}$ substrate with dielectric constant equals to $\varepsilon_{r}=4.4$ (loss tangent $=$ 0.018 ) and thickness $h=1.6 \mathrm{~mm}$ [20].

The selection of the circular disc antenna can be justified by its good performance, compact size, and ease of integration [14]. The microstrip antenna elements working at UWB frequency range $(f=3.1-10.6 \mathrm{GHz})$ are placed collinearly along the $\mathrm{x}$-axis, and the spacing between antenna array elements is approximately equal to $0.35 \lambda_{0}$ of the lowest frequency band (measured from element centre to centre).

As mobile terminals; such as handsets and PDAs have become smaller, the design of smaller antenna elements are required, thus, the dimensions of the monopoles should be further reduced. The antenna is formed by a metallic disc of radius $R=12 \mathrm{~mm}$, and it has a partial ground plane printed on back side of the substrate with a ground length $L_{g}=93$ $\mathrm{mm}$, and a ground width $W_{g}=10.6 \mathrm{~mm}$.

The total dimensions of UWB antennas are: $93 \times 47 \times 1.6$ $\mathrm{mm}^{3}$ (corresponds approximately $0.95 \lambda_{0} \times 0.49 \lambda_{0} \times 0.016$ $\left.\lambda_{0}\right)$ to be suitable for most mobile PCB circuit boards, other antenna dimensions obtained after optimisation process are illustrated as follows:
Table 1. Detailed dimensions of the UWB antenna

\begin{tabular}{|c|c|}
\hline Parameters & Values \\
\hline frequency $(f)$ & $3.1-10.6 \mathrm{GHz}$ \\
\hline height of substrate $(h)$ & $1.6 \mathrm{~mm}$ \\
\hline ground length $(\mathrm{Lg})$ & $93 \mathrm{~mm}$ \\
\hline ground width $(W g)$ & $10.6 \mathrm{~mm}$ \\
\hline substrate length $(L s)$ & $93 \mathrm{~mm}$ \\
\hline substrate width $(W)$ & $47 \mathrm{~mm}$ \\
\hline circular patch radius $(R)$ & $12 \mathrm{~mm}$ \\
\hline space $(S)$ & $0.35 \lambda_{0}$ \\
\hline feed line length $\left(L_{f}\right)$ & $12.5 \mathrm{~mm}$ \\
\hline feed line width $\left(W_{f}\right)$ & $1.5 \mathrm{~mm}$ \\
\hline gap $(g)$ & $0.5 \mathrm{~mm}$ \\
\hline
\end{tabular}

The distance $(g)$ between the ground plane and the antenna radiating element effects the impedance bandwidth and hence the gap distance had been optimised here at $g=0.5$ $\mathrm{mm}$. Moreover, for getting a better impedance matching (particularly in the higher frequencies), two small rectangular slots (denoted by $S_{1}$ and $S_{2}$ ) of compact dimensions $1.6 \mathrm{~mm}$ $\times 6 \mathrm{~mm}$ were introduced on the common ground plane to enhance the impedance bandwidth. These slots are cut on the upper edge of the ground plane underneath each feed line. Finally; the radiating circular patch is made up of a very thin copper sheet with a thickness of $0.1 \mathrm{~mm}$.

\section{B) Multiple antennas and decoupling structure for coupling reduction}

The layout of the proposed wideband decoupling structure is illustrates in the Fig. 2(a).The proposed structure composes of modified metallic patch like $\mathrm{T}$ on the upper side with optimised dimensions $L_{2}=9 \mathrm{~mm} \times W_{l}=36 \mathrm{~mm}$, another smaller metallic patch like inverse $\mathrm{T}$ on the lower side with optimised dimensions $L_{3}=6 \mathrm{~mm} \times W_{2}=17 \mathrm{~mm}$ are joint and subtracted by four half-circular slots (dual half-circular in the upper side and another dual smaller half-circular on the lower side) to form a parasitic strip that has been applied as a compact wideband planar decoupling structure between UWB antennas, The structure is symmetrical along the $\mathrm{Z}$ axis from the centre. The proposed wideband decoupling structure has longer current paths that it could work in the low-frequency range.

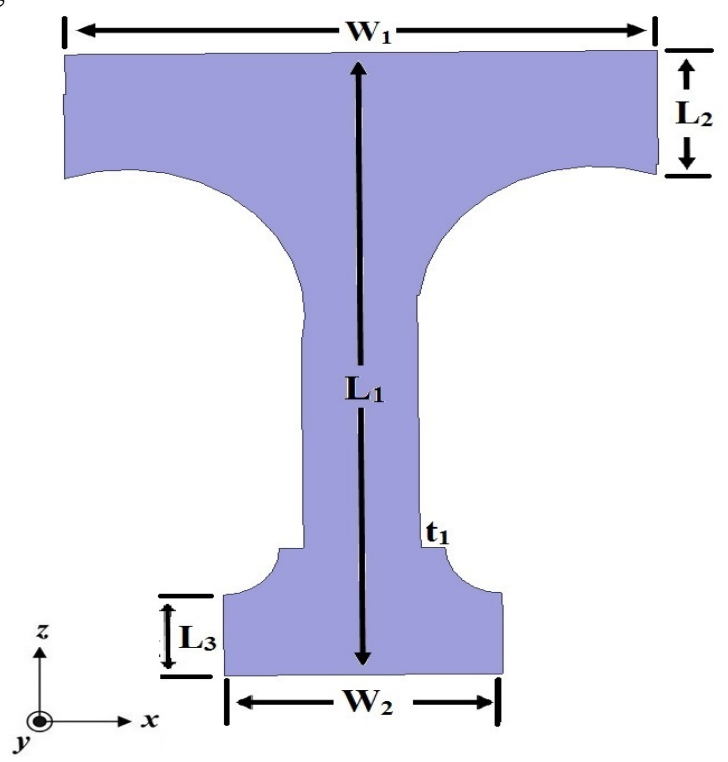

(a) 

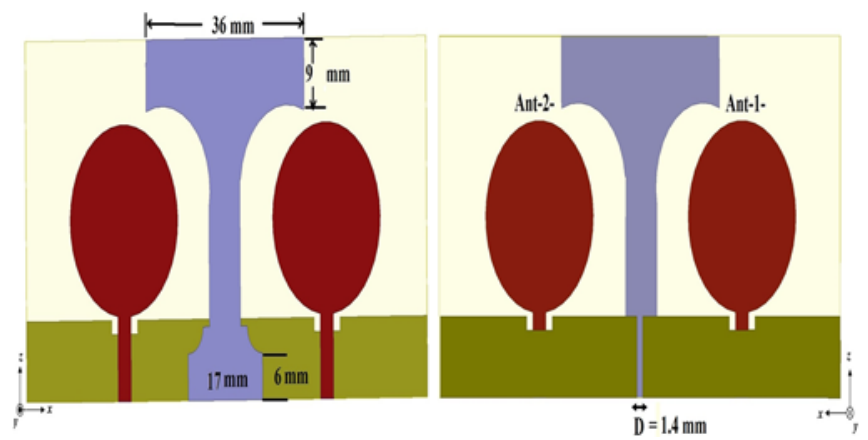

(b)

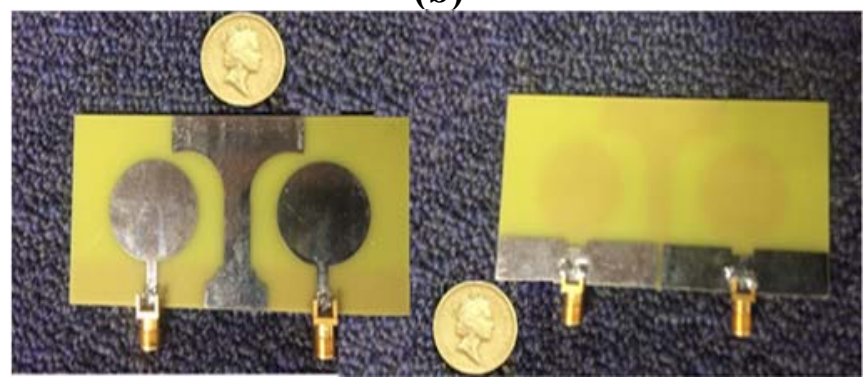

(c)

Fig. 2. (a) Detailed layout of the proposed decoupling structure (b) Schematic UWB-MIMO antenna with decoupling structure (Front and Rear view) (c) A prototype of the fabricated diversity antenna (Top view and Back view).

The parameters given in Fig. 2(a) were optimised using the simulation software (HFSS) and the detailed optimum dimensions of the proposed decoupling structure used in this work are written in Table 2.

Table 2 Detailed dimensions (in $\mathrm{mm}$ ) of the proposed structure

\begin{tabular}{|l|c|}
\hline \multicolumn{1}{|c|}{ Optimised parameters } & $\begin{array}{c}\text { Values } \\
\text { in } \mathrm{mm}\end{array}$ \\
\hline Length of the proposed structure, $L_{1}$ & 47 \\
\hline upper width of the proposed structure, $W_{1}$ & 36 \\
\hline Height of the top portion of T-shaped strip, $L_{2}$ & 9 \\
\hline lower width of the proposed structure, $W_{2}$ & 17 \\
\hline $\begin{array}{l}\text { Height of bottom portion of inverse } T \text {-shaped } \\
\text { strip, } L_{3}\end{array}$ & 6 \\
\hline Span on one side, $t_{1}$ & 1.5 \\
\hline
\end{tabular}

The proposed wideband planar decoupling structure was then inserted between the dual-monopole antenna elements to reduce mutual coupling, it will provide additional coupling paths and reduce directly induced coupling currents in the radiating elements (as presented in next section).

\section{PERFORMANCE OF THE MULTIPLE ANTENNAE}

\section{A) Simulated scattering parameters}

The return loss (reflection coefficient) and the transmission loss (mutual coupling) for the dual antenna array elements without and with the proposed decoupling structure are plotted in Fig. 3(a) and Fig. 3(b); respectively. Figure 3(a) illustrates the reflection coefficient performance; it was observed that the UWB antennas in both cases (without and with structure) has a wide broadband bandwidth ranging from 3 to $11 \mathrm{GHz}$ (for $\mathrm{S}_{11}<-10 \mathrm{~dB}$ ). Thus the array antenna satisfies the impedance matching requirement for the entire UWB range specified by the FCC. All these analyses were conducted with one antenna element transmitting and the other antenna terminated with $50 \Omega$ load.

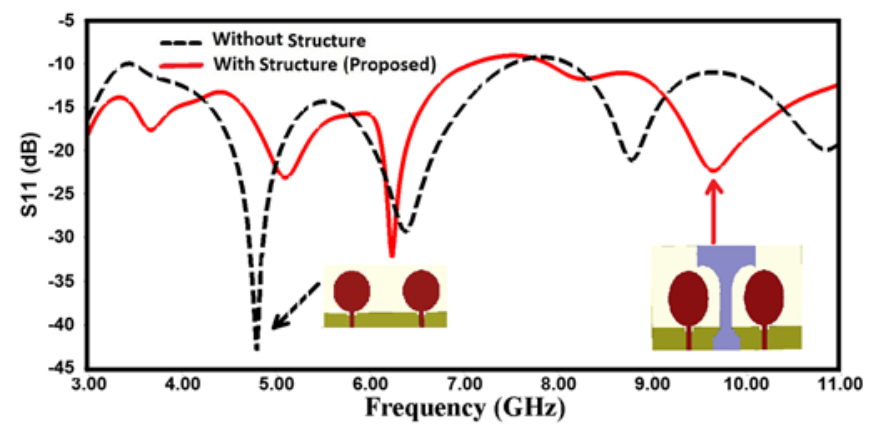

(a)

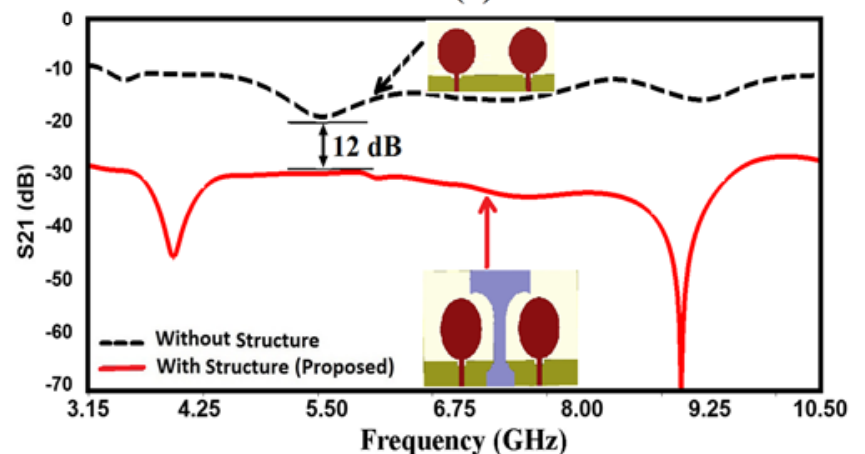

(b)

Fig. 3. The simulated scattering parameters of proposed UWB-MIMO antenna without (dashed line-black colour) and with decoupling structure (solid line-red colour). (a) Reflection coefficient $\left(\mathrm{S}_{11}\right)$ and (b) Transmission coefficient $\left(\mathrm{S}_{21}\right)$.

The mutual coupling between antenna elements can be determined from scattering parameters; $\mathrm{S}_{21}$ or $\mathrm{S}_{12}$. The simulated mutual coupling is shown in Fig. 3(b).

An isolation of less than $-31 \mathrm{~dB}$ has been achieved through the entire UWB band (more than $12 \mathrm{~dB}$ improvement over the reference antenna). This result satisfies the required condition for mutual coupling between the antennas for proper operation of the MIMO system in the UWB frequency range.

\section{B) Isolation mechanism and working with the various decoupling structures}

The direct mutual coupling between two antenna elements can be cancelled out by properly adding an extra indirect coupling path. A proper design aims at creating an indirect signal coming via the extra coupling path that opposes the signal going directly from element to element. If the two amplitudes are comparable and out of phase, the two signals add up destructively, and the mutual interaction is considerably reduced. An extra requirement is that the inserted decoupling structure should not significantly degrade the radiation properties.In the approach followed here, by placing and adding a non-resonating and parasitic decoupling structure between antennas, extra active coupling paths can be created. The coupled radiation introduces induced currents on the neighbouring antenna. The proposed wideband decoupling structure can also capture the near coupling fields and converts them in surface currents to be shorted with ground plane and such that multiple coupling paths reduce the direct strong coupling between ports and hence reducing the mutual coupling. 


\section{DRAFT}

In this work, the dimensions of the proposed decoupling structure were optimised to obtain a maximum surface currents pickup strategy.

The surface currents analyses are presented in the next section.

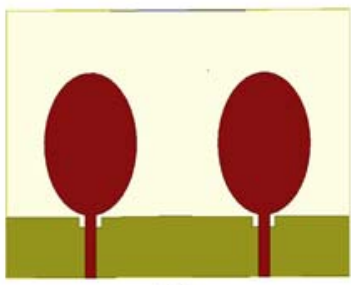

(a)

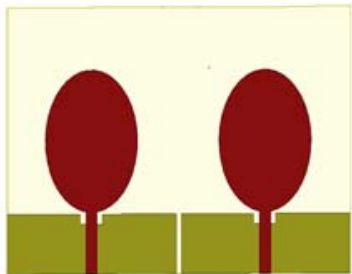

(b)

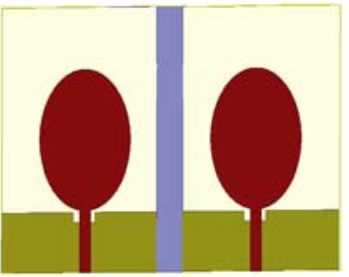

(c)

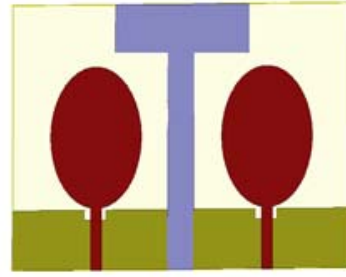

(d)

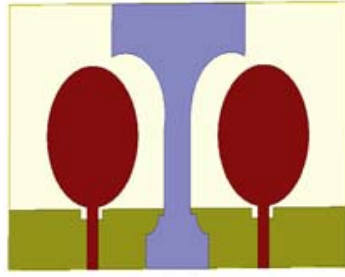

(e)

Fig. 4. UWB-MIMO antenna elements with different geometrical models. (a) Without decoupling structure (Model I), (b) With a centre slot on the ground (Model II), (c) With conventional rectangular shaped decoupling structure ( Model III), (d) With T-shaped decoupling structure (Model IV), and (e) With proposed wideband planar decoupling structure (Model V).

To further inspect the performance of the MIMO antenna and investigate the best decoupling structure arrangement to be utilised and used in the UWB-MIMO antenna configuration, five different geometrical models are given in Fig. 4, and individual simulated $S_{21}$ parameter variations plot for these five models is presented in Fig. 5.

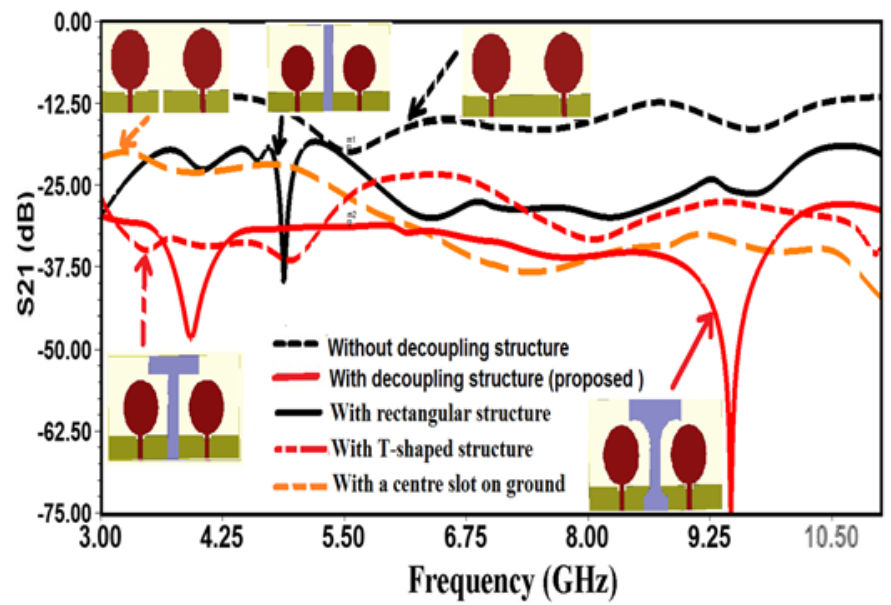

Fig. 5. Simulated $S_{21}$ parameters for different geometrical models of UWB MIMO antenna

However, inserting both a centre slot in common ground (Model II) and a conventional rectangular structure (Model III), as given in Fig. 4(b) and Fig. 4(c); respectively, help to improve isolation between the antenna array but not for the entire UWB range, only a real enhancement, $\mathrm{S}_{21} \leq-24 \mathrm{~dB}$ can be seen in the higher frequencies range. To further increase the isolation between antennas especially in lower frequencies range of the UWB operation; a T-shaped structure (Model IV) has been presented in the middle of the substrate as illustrated in Fig. $4(d)$, thus; the $\mathrm{S}_{21}$ parameter here has some good values (below $-28 \mathrm{~dB}$ ) towards lower UWB frequencies but remains with high coupling as is to be expected in higher frequencies $(>5.5 \mathrm{GHz})$. Finally; by introducing the proposed wideband decoupling structure (Model V) as seen in Fig. 4(e), an excellent isolation of less than $-31 \mathrm{~dB}$ (more than $12 \mathrm{~dB}$ improvement over the reference) has been achieved through the entire UWB band, and hence this case can satisfy the requirements of an applicable UWB operation with the highest isolation.

\section{C) Simulated radiation patterns, gain and radiation efficiency}

The orientation of the proposed antenna with respect to the coordinate system is shown in Fig. 1. This section presents the study performed on the effect of far-field radiation patterns as a comparison between both cases (with and without inserting the proposed wideband decoupling structure).

The simulated far-field radiation patterns are normalised with respect to the realised gain on the major principal planes (Y-Z, and $\mathrm{X}-\mathrm{Y}$ planes) in both prototypes, without and with wideband decoupling structure, are shown in Fig. 6.
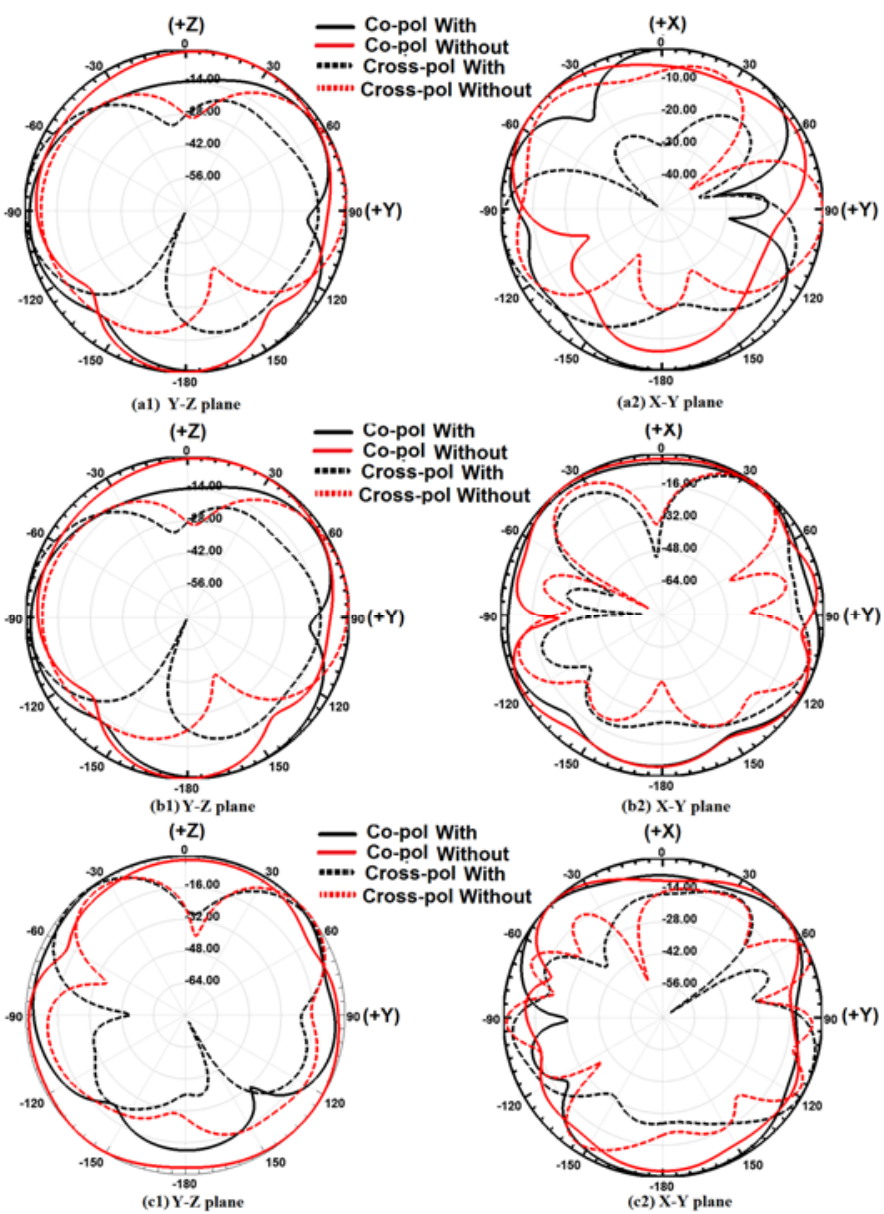

Fig. 6. The simulated $2 D$ radiation patterns without and with the proposed decoupling structure: (a1) $\mathrm{y}-\mathrm{z}$ plane, and (a2) $\mathrm{x}-\mathrm{y}$ plane at $4 \mathrm{GHz}$; (b1) $\mathrm{y}-\mathrm{z}$ plane, and (b2) $\mathrm{x}-\mathrm{y}$ plane at $6 \mathrm{GHz}$; and (c1) $\mathrm{y}-\mathrm{z}$ plane, and (c2) $\mathrm{x}-\mathrm{y}$ plane at $8 \mathrm{GHz}$; respectively, with port 1 excited.(solid line: co-pol, dashed line: crosspol, black colour: with, and red colour: without) 


\section{DRAFT}

In general, we can see that the overall radiation patterns are relatively stable across the different UWB frequencies. Still nearly omnidirectional patterns are obtained at various frequencies (4 GHz, $6 \mathrm{GHz}$ and $8 \mathrm{GHz}$ ) before and after inserting the wideband decoupling structure, no significant degradation of radiation patterns are noticed between the two designs (with and without decoupling structure) in $\mathrm{Y}-\mathrm{Z}$ and $\mathrm{X}$ $\mathrm{Y}$ planes. However, an enhancement in radiation characteristics helps to improve the peak gain of the antenna, the gain variation without decoupling structure is $1.4 \mathrm{dBi}$, however, this difference reduces to $<0.5 \mathrm{dBi}$ with a peak gain of $3.5 \mathrm{dBi}$ at a frequency $(9 \mathrm{GHz})$, when the proposed wideband decoupling structure is inserted, which makes it more consistent over the radiating bandwidth. Since the isolation is achieved by using a wideband parasitic decoupling structure, there is the possibility of a reduction in radiation efficiency. The antenna radiation efficiency is simulated with and without wideband decoupling structure. The comparison is provided in Fig. 7.
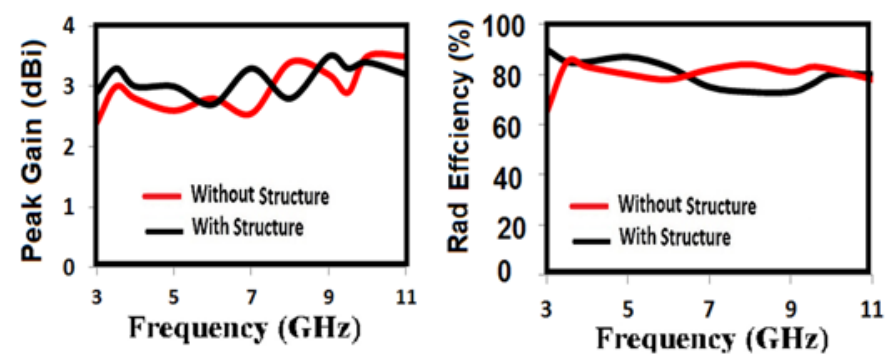

Fig. 7. Simulated antenna gain variation (left side) and radiation efficiencies (right side) over the radiating band of the proposed UWB-MIMO antenna.

The radiation efficiency of UWB antennas remains above $70 \%$ in the complete frequency band. The radiation efficiency only varies by $<10 \%$ in the whole band which certifies that the parasitic wideband decoupling structure does not have any notable effect on radiation characteristics. The radiation efficiency at the lower UWB frequencies is better for diversity antenna with decoupling structure which indicates that the wideband decoupling structure reduces the return loss at lower frequencies. At the upper UWB frequencies, the radiation efficiency with decoupling structure is less than an antenna without wideband decoupling structure which indicates an increase in mismatch loss at higher frequencies.

\section{D) Simulated surface currents distribution}

To further elaborate the effectiveness of the insertion of the decoupling structure, the degree of isolation in the proposed UWB antenna can be observed by presenting surface currents distribution.

Fig. 8(a-c) shows the currents distribution with and without the wideband decoupling structure at different three frequencies ( $4 \mathrm{GHz}, 6 \mathrm{GHz}$ and $8 \mathrm{GHz}$ ) when $A n t-1$ - is excited while Ant-2- is terminated with a load impedance of $50 \Omega$. The effects of the proposed wideband decoupling structure on the currents distribution can clearly be noticed by comparing with those without structure. The surface currents are absorbed by wideband decoupling structure, and thus it ameliorates the port isolation between two UWB monopoles.

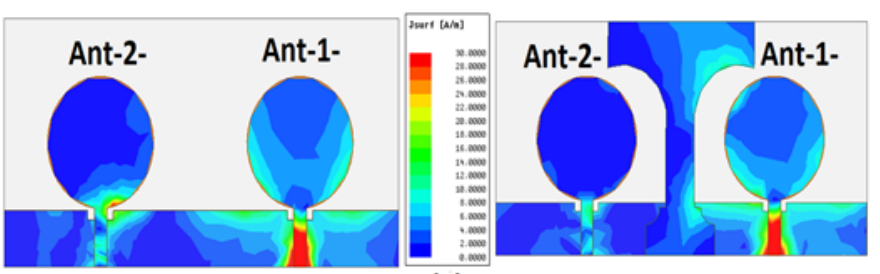

(a)

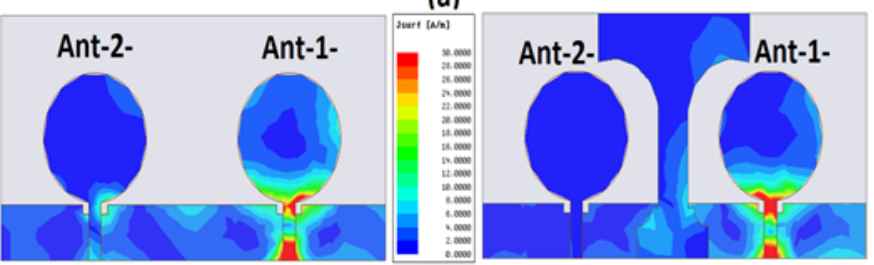

(b)

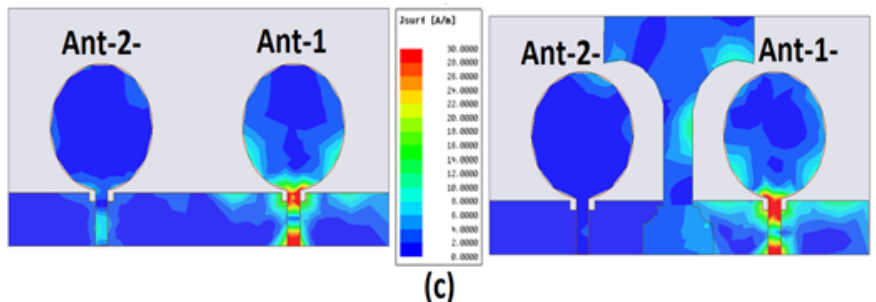

Fig. 8. Simulation of surface currents distribution on the proposed antenna array without structure (left side) and with decoupling structure (right side), when the first antenna is excited and the second antenna is terminated with a 50 load at a frequency: (a) $4 \mathrm{GHz}$, (b) $6 \mathrm{GHz}$, (c) $8 \mathrm{GHz}$.

It is observed from Fig. $8(a-c)$ that less amount of surface currents are induced in the second UWB antenna because most of the antenna's direct coupling field is concentrated in the planar wideband decoupling structure; this shows the creation of additional current paths between the two radiating elements and prevents most of the induced currents to be transferred towards the second antenna. The effect is same when Ant-2was excited while Ant-1- was terminated with $50 \Omega$ load.

\section{E) Diversity performance}

The Envelope Correlation Coefficient (ECC) between antenna elements is another crucial parameter and one of the most important parameters as it indicates and evaluates the $\mathrm{MIMO}$ /diversity performance, because it is directly related with the antenna scattering parameters and may significantly degrade diversity system performance.

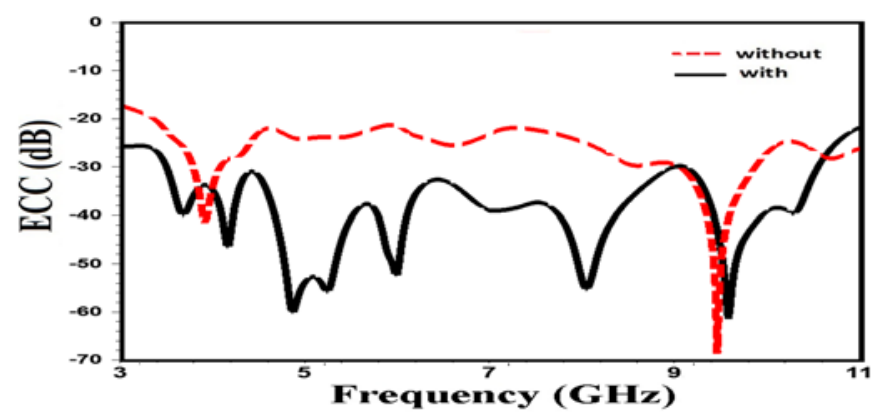


Fig. 9. Simulated envelope correlation coefficient of the proposed UWBMIMO antenna without (dashed line-red colour) and with wideband decoupling structure (solid line-black colour).

For dual $(2 \times 2)$ MIMO antenna system, the Envelope Correlation Coefficient (ECC) equation using the scattering parameters is given by [17].

$$
\rho_{12}=\frac{\left|S^{*}{ }_{11} S_{21}-S^{*}{ }_{12} S_{22}\right|^{2}}{\left(1-\left|S_{11}\right|^{2}-\left|S_{21}\right|^{2}\right)\left(1-\left|S_{22}\right|^{2}-\left|S_{12}\right|^{2}\right)}
$$

In this work, ECC $\left(\rho_{12}\right)$ can be calculated using (1) under some assumptions: ideal and uniform propagation multipath environment, antenna system is lossless and the one of the antenna elements is excited separately while keeping the other antennas matched terminated.

In Figure 9, the envelope correlation coefficient for the antenna elements with and without the proposed wideband decoupling structure is shown against the working frequency. From the simulated results, the maximum envelope correlation coefficient of $-29 \mathrm{~dB}$ over the UWB frequency range of antenna elements with the proposed wideband decoupling structure is smaller than that of the array elements without structure.

This observation indicates better behaviour and a good diversity performance of the antenna system will be achieved by using the proposed wideband planar decoupling structure.

\section{FABRICATION AND EXPERIMENTAL DEMONSTRATION}

The proposed UWB antennas were fabricated by using the PCB material of inexpensive $\mathrm{FR}_{4}$ substrate having a thickness of $1.6 \mathrm{~mm}$, dielectric permittivity constant of 4.4 (with loss tangent of 0.017). The microstrip lines were fed through $50 \Omega$ SMAs. Photographs of fabricated UWB-MIMO antennas without and with wideband decoupling structure are illustrated before in Fig. 1(b) and Fig. 2(c); respectively.

\section{A) Simulated and measured scattering parameters}

To validate the simulation results, the proposed UWB antenna had been fabricated, tested, measured and then compared with simulated results.

The performance of the UWB-MIMO antenna has been verified through a measurement performed by means of Agilent Technologies N5230A PNA-L RF network vector analyser inside Brunel University London.

The measured and simulated scattering parameter plots (return loss and transmission loss) are presented in Fig. 10(a) and Fig. $10(b)$; respectively.

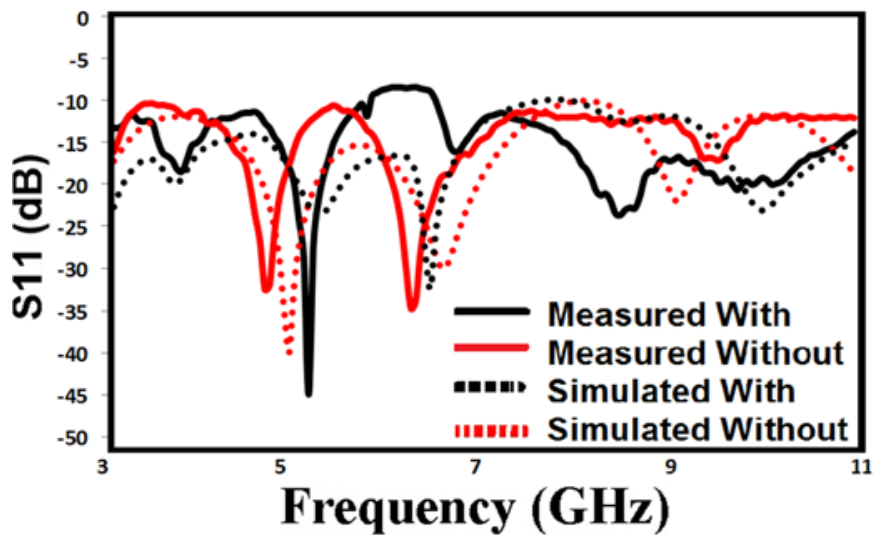

(a)

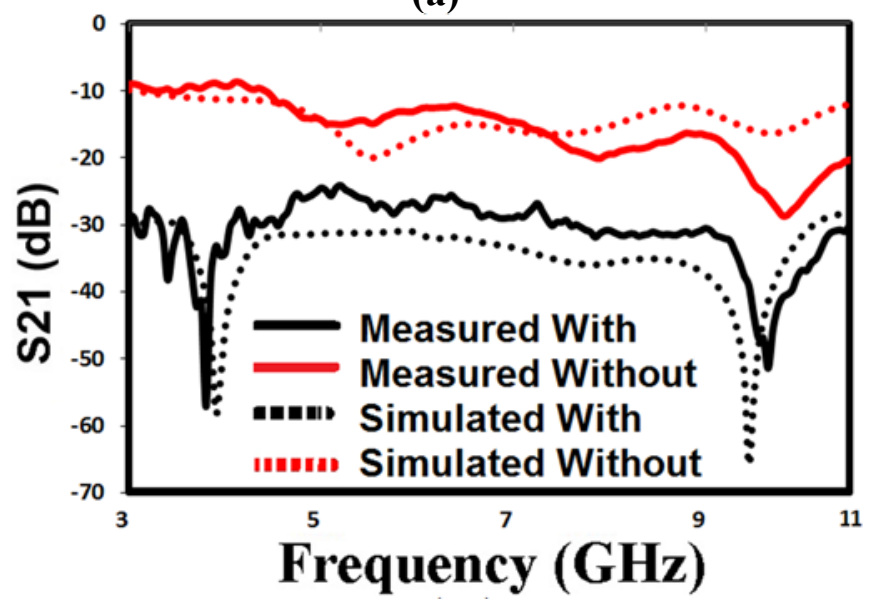

(b)

Fig. 10. Comparison of simulated and measured scattering parameters without and with a wideband decoupling structure. (a) Reflection coefficient $\left(\mathrm{S}_{11}\right)$ and (b) Transmission coefficient $\left(\mathrm{S}_{21}\right)$.

Figure 10(a) shows the measured and simulated return loss of the impedance bandwidth $\left(\mathrm{S}_{11}<-10 \mathrm{~dB}\right)$ comparatively between the dual UWB antennas with and without the proposed wideband decoupling structure.

It is observed that the proposed antennas has a wide measured bandwidth $7.5 \mathrm{GHz}$ and covers the whole UWB band ranging $3.1-10.6 \mathrm{GHz}$ with a return loss better than $-10 \mathrm{~dB}$ that satisfy the requirements of UWB operation.

A reasonably good agreement can be noticed between the measured and simulated plots although a slight difference between these results can be noticed.

That may be attributed to factors such as an inaccuracy in the fabrication process, variation in the quality of the substrate, and mismatch effect of SMA connectors.

In all these measurements, one port is excited and the other terminated by the standard $50 \Omega$ loads.

Fig. 10(b) shows the measured and simulated mutual coupling comparatively between the dual UWB antennas with and without the proposed wideband decoupling structure.

The prototyped MIMO antenna has wide frequency range covers from 3 to $11 \mathrm{GHz}$ with the measured isolation less than $-27 \mathrm{~dB}$. 


\section{DRAFT}

These results agree well with the simulated results obtained before as shown previously in Fig. 3. A slight deviation can be attributed to the fabrication tolerances. From this experimental verification, it can be concluded that the proposed wideband decoupling structure can reduce the mutual coupling between antenna array elements.

\section{B) Simulated and measured radiation patterns.}

The radiation patterns of the proposed UWB-MIMO antenna were measured in an anechoic chamber of the University of Greenwich at various frequencies $(4 \mathrm{GHz}, 6$ $\mathrm{GHz}$ and $8 \mathrm{GHz}$ ). The measured and simulated far-field radiation patterns are normalised with respect to the realised gain without and with the proposed wideband decoupling structure are presented in Fig. 11 and Fig. 12; respectively:
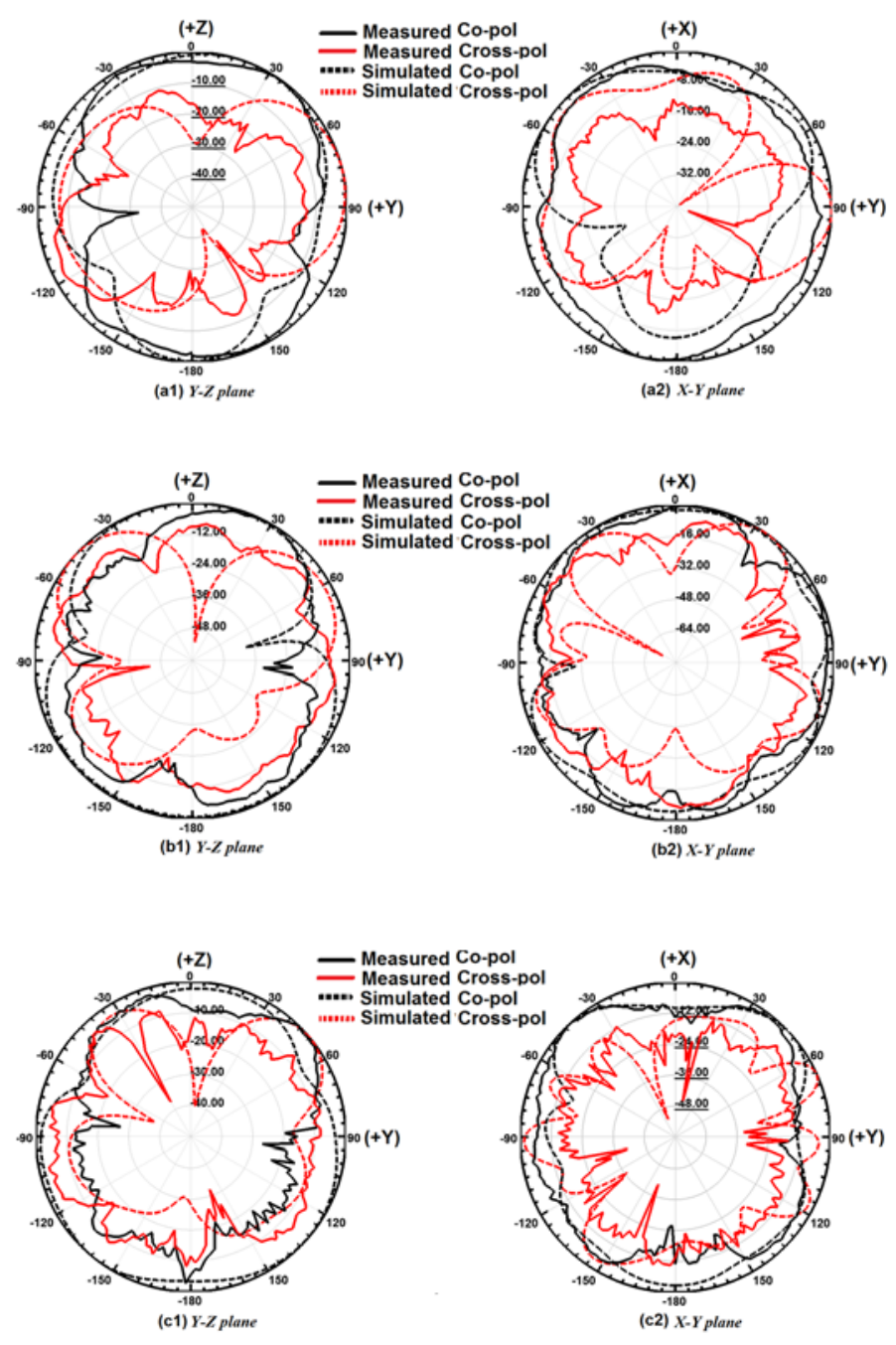

Fig. 11. Measured versus simulated radiation patterns (normalised) without the proposed decoupling structure: (a1) $y-z$ plane, and (a2) $x-y$ plane at 4 $\mathrm{GHz}$; (b1) $\mathrm{y}-\mathrm{z}$ plane, and (b2) $\mathrm{x}-\mathrm{y}$ plane at $6 \mathrm{GHz}$; and (c1) $\mathrm{y}-\mathrm{z}$ plane, and (c2) $\mathrm{x}-\mathrm{y}$ plane at $8 \mathrm{GHz}$; respectively, with port 1 excited.(Solid line: measured, broken line: simulated, black colour: co-pol, and red colour: crosspol).
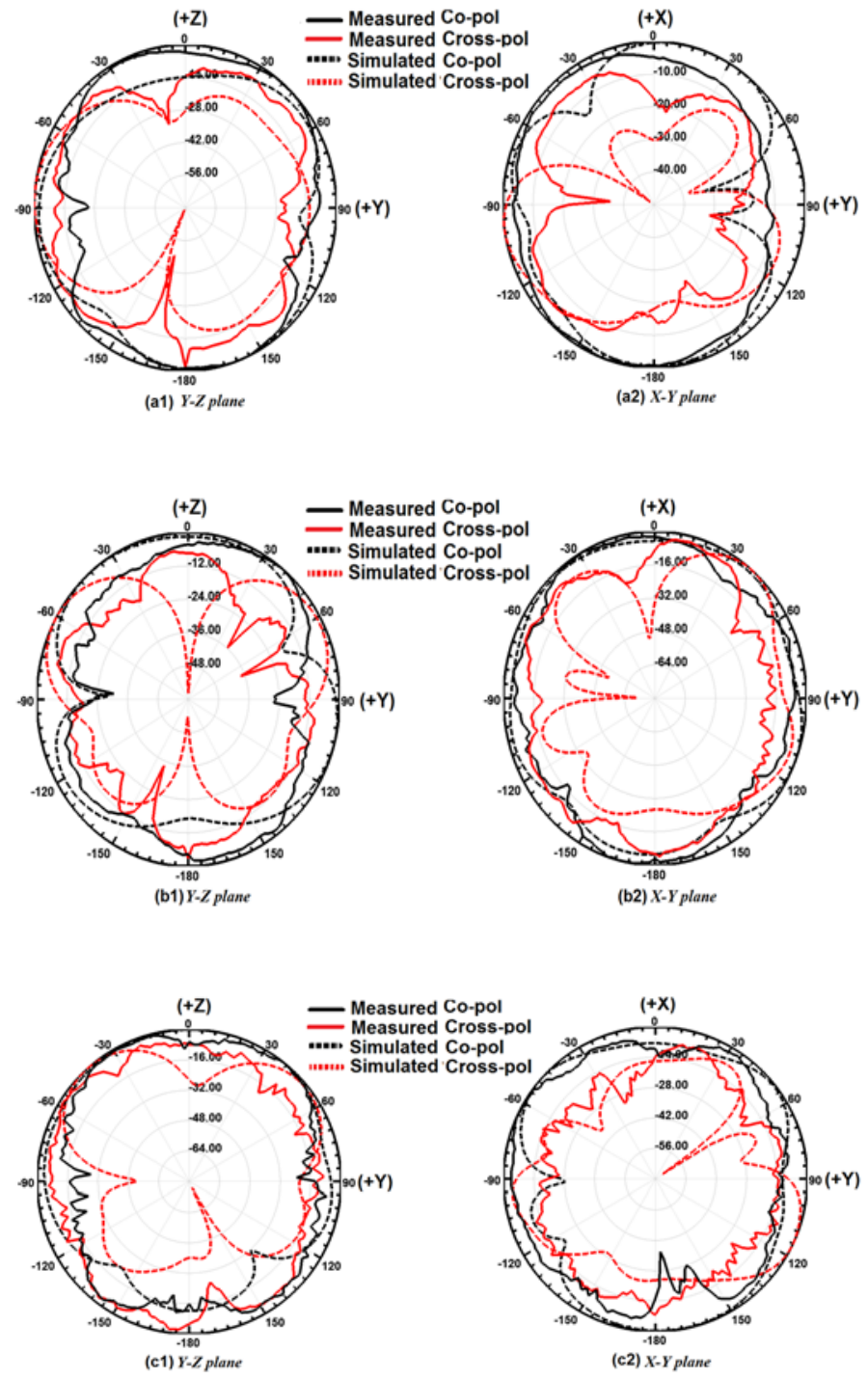

Fig. 12. Measured versus simulated radiation patterns (normalised) with the proposed decoupling structure: (a1) $y-z$ plane, and (a2) $x-y$ plane at $4 \mathrm{GHz}$; (b1) $\mathrm{y}-\mathrm{z}$ plane, and (b2) $\mathrm{x}-\mathrm{y}$ plane at $6 \mathrm{GHz}$; and (c1) $\mathrm{y}-\mathrm{z}$ plane, and (c2) $\mathrm{x}-\mathrm{y}$ plane at $8 \mathrm{GHz}$; respectively, with port 1 excited.(Solid line: measured, broken line: simulated, black colour: co-pol, and red colour: cross-pol).

During the measurement, one of the input ports was excited, and the other was terminated with a $50 \Omega$ load. In general; no significant difference is observed between the different copolarisation and cross polarisation patterns of the measured and the simulated results. The radiation patterns are good omnidirectional in the major planes (Y-Z and X-Y planes). However, some nulls appear after inserting the proposed wideband decoupling structure especially in the measured cross-polarised. Moreover, there are some slight discrepancies between the measured and the simulated results in the different frequency band of interest, which are probably due to the effect of the SMA connectors and implementation imperfections. 


\section{COMPARISON WITH OTHER WORK}

Table 3 presents a summarised comparison of our proposed UWB-MIMO antenna against other array works previously reported and recently published in the literature. The UWB antennas are tabulated in terms of various criteria such as bandwidth, mutual coupling level, geometric size and complexity, and isolation technique. Therefore the proposed UWB-MIMO antenna array has some outstanding characteristics because of the compact size, geometric simplicity, broad bandwidth, low correlation and good diversity performance. All these results demonstrate that the proposed MIMO antenna configuration is a good candidate for some UWB portable devices.

Table 3. Comparison with previous works of UWB-MIMO antenna designs

\begin{tabular}{|c|c|c|c|c|c|c|c|}
\hline $\begin{array}{c}\text { Ref. } \\
\text { No. }\end{array}$ & $\begin{array}{c}\text { Frequency range, } \\
\text { GHz at }-10 \mathrm{~dB}\end{array}$ & $\begin{array}{c}\text { Mutual } \\
\text { coupling } \\
\text { level,-dB }\end{array}$ & $\begin{array}{c}\text { Volume } \\
\mathrm{mm}^{3}\end{array}$ & $\begin{array}{c}\text { Space, } \\
\lambda_{0}\end{array}$ & Isolation technique & $\begin{array}{c}\text { Geometric } \\
\text { complexity }\end{array}$ & Main geometry \\
\hline$[3]$ & $3.1-5$ & -22 & 1120 & 0.5 & $\begin{array}{c}\text { Neutralization line } \\
\text { (NL) }\end{array}$ & Complex & $\begin{array}{c}\text { Dual circular monopole } \\
\text { antenna elements }\end{array}$ \\
\hline$[4]$ & $3-6$ & -21 & 4650 & 0.5 & $\begin{array}{c}\text { Dual-layer } \\
\text { EBG structure }\end{array}$ & Complex & $\begin{array}{c}\text { Dual radiating monopoles } \\
\text { with slits in the ground }\end{array}$ \\
\hline$[5]$ & $3.1-10.6$ & -18 & 1920 & 0.5 & DGS structure & Complex & a printed fractal antenna \\
\hline$[6]$ & $2.8-8$ & -17 & 5429 & 0.4 & $\begin{array}{c}\text { Separated ground } \\
\text { plane }\end{array}$ & Simple & $\begin{array}{c}\text { Dual circular shaped } \\
\text { monopoles radiator }\end{array}$ \\
\hline$[7]$ & $3-12$ & -15 & 5120 & 0.5 & $\begin{array}{c}\text { Resonator slot in } \\
\text { between }\end{array}$ & Medium & $\begin{array}{c}\text { Dual identical rectangular } \\
\text { with a circular slot }\end{array}$ \\
\hline$[8]$ & $1.8-6.5$ & -20 & 29768 & 0.5 & $\begin{array}{c}\text { Spatial and angular } \\
\text { variation }\end{array}$ & Medium & $\begin{array}{c}\text { Circular slot antenna with a } \\
\text { stepped ground plane }\end{array}$ \\
\hline$[15]$ & $3.1-10.6$ & -20 & 1120 & 0.4 & $\begin{array}{c}\text { Inserting stub on } \\
\text { common ground }\end{array}$ & Complex & $\begin{array}{c}\text { Compact dual monopole- } \\
\text { antenna elements }\end{array}$ \\
\hline$[16]$ & $2.27-10.2$ & -20 & 3072 & 0.5 & $\begin{array}{c}\text { Inserting stub on } \\
\text { common ground }\end{array}$ & Medium & $\begin{array}{c}\text { Dual Y-shaped radiating } \\
\text { monopoles elements }\end{array}$ \\
\hline $\begin{array}{c}\text { This } \\
\text { work }\end{array}$ & $3.1-10.6$ & -31 & 6992 & 0.35 & $\begin{array}{c}\text { Planar decoupling } \\
\text { structure }\end{array}$ & Simple & $\begin{array}{c}\text { Dual circular monopole } \\
\text { UWB-MIMO antenna } \\
\text { elements }\end{array}$ \\
\hline
\end{tabular}

\section{CONCLSIONS}

A new monopole MIMO antenna with high isolation and a compact size of $93 \times 47 \times 1.6 \mathrm{~mm}^{3}$ had been designed and developed for UWB application. The prototype of the antenna was printed on inexpensive FR4 substrate. A simple but highly efficient isolation technique is proposed. The effectiveness of the proposed wideband decoupling structure has been shown to be useful in achieving compactness and better isolation of less than $-31 \mathrm{~dB}$ is obtained through the entire UWB frequency range for an antenna spacing less than $0.35 \lambda_{0}$ of the lowest frequency. The simulations agree well with the measurements including both scattering parameters and far field radiation patterns properties. Moreover, analysis results (theoretically and practically) show that the proposed UWBMIMO antenna guarantees an entire UWB bandwidth with high isolation and keeps nearly omnidirectional radiation performance successfully. Finally the antenna has been compared in detail with other UWB designs in terms of bandwidth, mutual coupling level, geometric size and an implementation complexity. All results indicate that our proposed antenna array has more advantages than other suggestions in points of these criteria and it can be capable of employing in some portable devices such as mobile handsets or laptops using UWB technology combined with MIMO techniques.

\section{REFERENCES}

[1] C. A. Balanis, Antenna Theory: Analysis and Design, 3rd Edition. Hoboken, NJ: John Wiley \& Sons, Inc., 2005.

[2] K. M. Prasanna and S. K. Behera, "Compact two-port UWB MIMO antenna system with high isolation using a fork-shaped structure," 2013 International Conference on Communication and Signal Processing, 2013

[3] S. Zhang and G. F. Pedersen, "Mutual Coupling Reduction for UWB MIMO Antennas With a Wideband Neutralization Line," Antennas Wirel. Propag. Lett. IEEE Antennas and Wireless Propagation Letters, vol. 15, pp. 166-169, 2016.

[4] Q. Li, A. P. Feresidis, M. Mavridou, and P. S. Hall, "Miniaturized Double-Layer EBG Structures for Broadband Mutual Coupling Reduction Between UWB Monopoles," IEEE Trans. Antennas Propagat. IEEE Transactions on Antennas and Propagation, vol. 63, no. 3, pp. 1168-1171, 2015

[5] Y. Li, W. Li, C. Liu, and T. Jiang, "A printed diversity Cantor set fractal antenna for ultra wideband communication applications," Isape2012, 2012.

[6] M. Jusoh, M. F. Jamlos, M. R. B. Kamarudin, and M. F. B. A. Malek, "A Mimo Antenna Design Challenges For Uwb Application," Progress In Electromagnetics Research B PIER B, vol. 36, pp. 357-371, 2012.

[7] C.-X. Mao, Q.-X. Chu, Y.-T. Wu, and Y.-H. Qian, "Design And Investigation Of Closely-Packed Diversity Uwb Slot-Antenna With 


\section{DRAFT}

High Isolation,” Progress In Electromagnetics Research C, vol. 41, pp. 13-25, 2013.

[8] S.-Y. Lin and H.-R. Huang, "Ultra-wideband MIMO antenna with enhanced isolation," Microwave and Optical Technology Letters, vol. 51, no. 2, pp. 570-573, 2009.

[9] N. K. Kiem, H. N. B. Phuong, Q. N. Hieu, and D. N. Chien, "A compact printed $4 \times 4$ MIMO-UWB antenna with WLAN band rejection," 2013 IEEE Antennas and Propagation Society International Symposium (APSURSI), 2013.

[10] L. Liu, S. W. Cheung, and T. I. Yuk, "Compact MIMO Antenna for Portable Devices in UWB Applications," IEEE Trans. Antennas Propagat. IEEE Transactions on Antennas and Propagation, vol. 61, no. 8, pp. 4257-4264, 2013.

[11] T. S. P. See and Z. N. Chen, "An Ultrawideband Diversity Antenna," IEEE Trans. Antennas Propagat. IEEE Transactions on Antennas and Propagation, vol. 57, no. 6, pp. 1597-1605, 2009.

[12] K.-L. Wong, S.-W. Su, and Y.-L. Kuo, "A printed ultra-wideband diversity monopole antenna," Microwave and Optical Technology Letters Microw. Opt. Technol. Lett., vol. 38, no. 4, pp. 257-259, 2003.

[13] L. Liu, S. W. Cheung, and T. I. Yuk, "Compact MIMO Antenna for Portable UWB Applications With Band-Notched Characteristic," IEEE Trans. Antennas Propagat. IEEE Transactions on Antennas and Propagation, vol. 63, no. 5, pp. 1917-1924, 2015.

[14] A. I. Najam, Y. Duroc, and S. Tedjni, "Uwb-Mimo Antenna With Novel Stub Structure," PIER C Progress In Electromagnetics Research C, vol. 19, pp. 245-257, 2011.

[15] S. Zhang, Z. Ying, J. Xiong, and S. He, "Ultrawideband MIMO/Diversity Antennas With a Tree-Like Structure to Enhance Wideband Isolation," Antennas Wirel. Propag. Lett. IEEE Antennas and Wireless Propagation Letters, vol. 8, pp. 1279-1282, 2009.

[16] S. Hong, K. Chung, J. Lee, S. Jung, S.-S. Lee, and J. Choi, "Design of a diversity antenna with stubs for UWB applications," Microwave and Optical Technology Letters Microw. Opt. Technol. Lett., vol. 50, no. 5, pp. 1352-1356, 2008.

[17] J. Byun, J.-H. Jo, and B. Lee, "Compact dual-band diversity antenna for mobile handset applications,"Microwave and Optical Technology Letters, vol. 50, no. 10, pp. 2600-2604, 2008.

[18] Chebihi, A., C. Luxey, A. Diallo, P. Le Thuc, and R. Staraj, "A novel isolation technique for closely spaced PIFAs for umts mobile phones," IEEE Antennas and Wireless Propagation Letters,Vol. 7, pp.665-668, Nov. 2008.

[19] Chiu, C.-Y., C.-H. Cheng, R. D. Murch, and C. R. Rowell, "Reduction of mutual coupling between closely-packed antenna elements," IEEE Transactions on Antennas and Propagation,Vol. 55, No. 6, pp.17321738, Jun. 2007.

[20] Choi, S. H., J. K. Park, S. K. Kim, and J. Y. Park, "A new ultrawideband antenna for UWB applications," Microwave and Optical Technology Letters, Vol. 40, No. 5, pp.399-401, May 2004.

[21] M. S. Sharawi, Printed MIMO Antenna Engineering. Boston: Artech House, 2014.

[22] Z. Y. Li, Z. W. Du, and K. Gong, "A dual-slot diversity antenna with isolation enhancement using parasitic elements for mobile handsets," in Proc. Asia Pacific Microw. Conf., 2009, pp. 1821-1824.

[23] A. Y. Modi, C. A. Balanis, C. R. Birtcher, and H. N. Shaman, "Novel Design of Ultrabroadband Radar Cross Section Reduction Surfaces Using Artificial Magnetic Conductors," IEEE Transactions on Antennas and Propagation, vol. 65, no. 10, pp. 5406-5417, 2017.

[24] L. Gong, Y. Yang, K. Y. Chan, and R. Ramer, "RHCP patternreconfigurable spiral antenna biased with two DC signals," Microwave and Optical Technology Letters, vol. 56, no. 7, pp. 1636-1640, 2014.

[25] L. Gong, K. Y. Chan, and R. Ramer, "A reconfigurable spiral antenna with wide beam coverage," 2013 IEEE Antennas and Propagation Society International Symposium (APSURSI), 2013. 